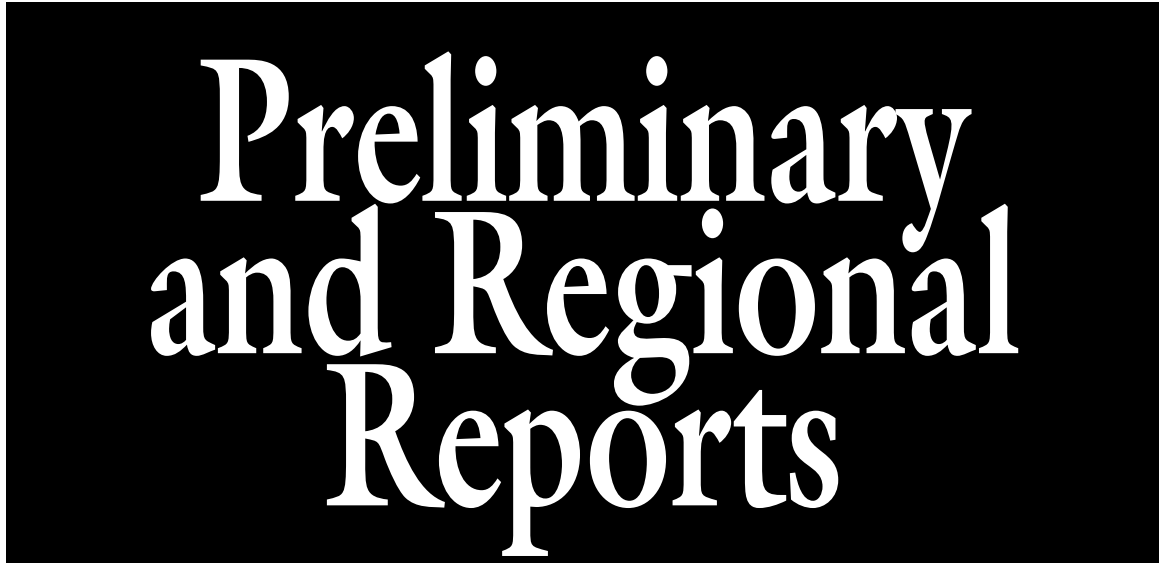

\title{
Importance of Hand Hygiene during the Harvesting of Strawberries
}

\author{
Angela Shaw ${ }^{1,4}$, Amanda Svoboda $^{1}$, Beatrice Jie ${ }^{1}$, Aura Daraba $^{1,2}$, \\ and Gail Nonnecke ${ }^{3}$
}

AdDITIONAL INDEX WORDs. Fragaria Xananassa, E. coli O157:H7, pre-harvest, cross contamination

SUMMARY. Foodborne outbreaks linked to poor hygiene indicate a need for education on the importance of hand hygiene during harvesting of fruit. This study simulated two potential scenarios (laboratory and field) that would lead to the transfer of Escherichia coli O157:H7 from hands to strawberries (Fragaria $\times$ ananassa), harvesters, and field plants. The potential of direct transfer of E. coli O157:H7 from contaminated "pig skin" hands to strawberries was shown in Scenario 1. The potential of $E$. coli $\mathrm{O} 157: \mathrm{H} 7$ being transferred from contaminated hands to strawberries during harvesting was shown in all treatments up to the 100th strawberry tested with a transfer rate of $71 \%$ ( 1 berry) to $45 \%$ ( 100 berries) of $E$. coli. Scenario 2 mimicked the "bacteria" transfer from the worker's contaminated hands to the workers' clothing and to the field with the use of glowing lotion. It was shown that contaminated hands can transfer "bacteria" to the worker's clothing, shoes, the picked strawberries, and the strawberry plants, weeds and straw mulch within the field (average spread of $50.25 \mathrm{ft}$ from starting point). The transfer rate varied from worker to worker. Hand hygiene and proper worker training are essential for foodsafe harvesting to avoid foodborne outbreak events.


ood agricultural practice (GAP) guidance recommends that employees maintain hand hygiene within the fields to ensure that foodborne pathogens are not transferred from hands to produce (Alzamora et al., 2000; Bihn and

This research project was supported by Iowa State University, College of Agriculture and Life Sciences with additional contributions from The North American Strawberry Growers

${ }^{1}$ Department of Food Science and Human Nutrition, Iowa State University, 2577 Food Science Building, Ames, IA 50011

${ }^{2}$ Food Science, Food Engineering and Applied Biotechnology Department, University Dunarea de Jos of Galati, Galati, Romania

${ }^{3}$ Department of Horticulture, Iowa State University, 105 Horticulture Hall, Ames, IA 50011

${ }^{4}$ Corresponding author. E-mail: angelaml@iastate.edu.
Gravani, 2006; U.S. Food and Drug Administration, 1998, 2009). Microbial contamination with E. coli Ol57:H7, Salmonella, Shigella, Staphylococcus, and norovirus on workers' hands are a major concern when hand washing stations are not readily available in farm-harvesting areas. Pate and
Nummer (2013) found that specialty crop production workers had high number of bacteria present on their hands and at multiple farms workers tested positive for Salmonella, Staphylococcus aureus, coliforms and generic E. coli. Our laboratory has shown that in greenhouse-grown strawberries, $E$. coli contaminated into strawberry soil at planting can survive 8 weeks and cross contaminate the soil and the harvested fruit (Laury-Shaw et al., 2015). The importance of hand hygiene and hand washing is a GAP recommendation that has been shown not to be followed regularly on-farm. A study within Iowa indicated that among 73 farms, hand washing stations and hand washing were areas that needed improvement (Ellis et al., 2005).

The European Commission $\mathrm{Eu}-$ ropean Food Safety Authority (EFSA) Biological Hazards panel in 2014 specifically recommended compliance with hygiene requirements to reduce the risk of Salmonella and norovirus during berry production (EFSA, 2014). These recommendations were in response to outbreaks with strawberries and other berries within the United States and aboard where poor personal hand hygiene as an attributing cause of illness, such as strawberries and highbush blueberries (Vaccinium corymbosum) in Massachusetts (Rodriguez et al., 2011; Todd et al., 2008, 2010). Although the number of outbreaks associated with strawberries and other berries is low in occurrence, the recent outbreak of 2011 along with a long history of linkages between personal hygiene and human pathogen outbreaks with berries (hepatitis A and norovirus), indicates the need for new knowledge regarding the ability and the conditions of E. coli Ol57:H7 transferring from contaminated hands to the fruit.

The purpose of this study was to determine the potential of $E$. coli

\begin{tabular}{llll}
\hline $\begin{array}{l}\text { Units } \\
\text { To convert U.S. to SI, } \\
\text { multiply by }\end{array}$ & U.S. unit & SI unit & $\begin{array}{l}\text { To convert SI to U.S., } \\
\text { multiply by }\end{array}$ \\
\hline 29.5735 & $\mathrm{fl} \mathrm{oz}$ & $\mathrm{mL}$ & 0.0338 \\
0.3048 & $\mathrm{ft}$ & $\mathrm{m}$ & 3.2808 \\
2.54 & inch $(\mathrm{es})$ & $\mathrm{cm}$ & 0.3937 \\
6.4516 & inch & $\mathrm{cm}^{2}$ & 0.1550 \\
0.4536 & $\mathrm{lb}$ & $\mathrm{kg}$ & 2.2046 \\
28.3495 & $\mathrm{Oz}$ & $\mathrm{g}$ & 0.0353 \\
$\left({ }^{\circ} \mathrm{F}-32\right) \div 1.8$ & ${ }^{\circ} \mathrm{F}$ & ${ }^{\circ} \mathrm{C}$ & $\left({ }^{\circ} \mathrm{C} \times 1.8\right)+32$
\end{tabular}


O157:H7 to be transferred from contaminated hands to strawberries during harvesting and the rate of transfer. Our research objectives were 1) to quantify the amount of strawberries that can be contaminated if picked by E. coli O157:H7contaminated hands (Scenario 1 ), and 2) to determine the magnitude of "bacteria" transfer, using a glowing lotion, from contaminated hands to workers, strawberries, and to the field (Scenario 2).

\section{Materials and methods}

Two scenarios of cross contamination by strawberry harvesters were designed to investigate the importance of hand hygiene during harvesting of strawberries. Scenario 1 mimics the direct transfer of E. coli O157:H7 from contaminated hands to strawberries during harvest. Scenario 2 mimics the transfer of "bacteria," via the use of glowing lotion, from contaminated hands to the person and to the field through a visual demonstration.

SCENARIO 1: TRANSFER OF E. COLI FROM CONTAMINATED HANDS TO STRAWBERRIES. Three adult trained volunteers with varying sizes of hands were requested to be the hand models for this experiment. Freshly harvested pig skin (Pine Ridge Farms, Des Moines, IA) was sterilized with surgical grade iodine solution (Dynarex, Orangeburg, NY) before the experiment. Pig skin was used in place of real hands due to the use of $E$. coli O157:H7 and the risk of bare hands in causing a foodborne illness in volunteers. The technique used in our experiment is widely used within the area of microbiology to show potential transfer from a hand to a vector and reduce the risk to the patron within the experiment (Barbero and Frasch, 2008). Hand shapes were cut out of pig skin in the following dimensions: $18.8 \times 9.5 \mathrm{~cm}, 17 \times 9.5 \mathrm{~cm}$, and $16 \times 8.2 \mathrm{~cm}$, to fit the three adult volunteers' hands (two females, one male) and to represent small, medium, and large adult hands (Fig. 1). The pig skin "hand" consisted of the thumb, three middle fingers, outer small finger, and palm. Hands were swabbed to ensure lack of presence of $E$. coli O157:H7.

Two strains of E. coli $\mathrm{Ol} 57: \mathrm{H7}$ (ATCC 35150 and ATCC 43894) were obtained from the culture collection of the Microbial Food Safety
Laboratory, IA State University, Ames. These strains were chosen due to their involvement in foodborne outbreaks resulting in hemorrhagic colitis in human cases in Oregon and Michigan. Escherichia coli O157:H7 inoculum was produced through frozen stock cultures being grown in tryptic soy broth (TSB; EMD, Gibbstown, $\mathrm{NJ})$ at $35^{\circ} \mathrm{C}$ over $2 \mathrm{~d}$, equally $(6 \mathrm{~mL})$ combined and centrifuged $(10,000$ $g_{\mathrm{n}}, 10 \mathrm{~min}, 4^{\circ} \mathrm{C}$ ) using a centrifuge (Sorvall Super T21; American Laboratory Trading, East Lyme, CT). Pellets were washed once in $0.85 \%$ $(\mathrm{w} / \mathrm{v})$ saline and suspended in fresh $0.85 \%(\mathrm{w} / \mathrm{v})$ saline to obtain a final viable cell concentration of $\approx 10^{9}$ colony-forming units $(\mathrm{cfu}) / \mathrm{mL}$. The viable counts of the washed cell suspensions were evaluated by serially diluting (10-fold) and surface plating samples on tryptic soy agar (Difco; Becton Dickinson, Franklin Lakes, $\mathrm{NJ})$ supplemented with $0.6 \%$ yeast extract (TSAYE). The cell suspensions were used to inoculate the pig skin "hands."

Ten milliliters of the prepared two-strain E. coli O157:H7 inoculum with a final concentration level of $10^{4} \mathrm{cfu} / \mathrm{cm}^{2}$, determined in prestudy tests to be the ideal amount for even distribution and recovery of the pathogen, were applied evenly onto each pig skin "hand" in a biosafety cabinet. The inoculated pig skin "hands" were provided $30 \mathrm{~min}$ for bacteria to attach to the surface under a biological safety hood. This methodology does not account for microbial death that may occur between harvest and consumption by consumers. Five of the inoculated pig skin "hands" samples were randomly analyzed to ensure that the final concentration on the "hand" was $10^{5} \mathrm{cfu} / \mathrm{cm}^{2}$ after the 30-min attachment period and to determine natural microbial death. Before touching the strawberries, the laboratory volunteers placed sterile gloves on their bare hands and then secured, on their hand, one of the three sizes of the pig skin "hand" using sterilized rubber bands (Fig. 1).

Strawberries were tested for the presence of E. coli O157:H7 as controls in this experiment before use. Strawberries attached to the inflorescence branches (peduncle and pedicels) were sourced from a local strawberry grower (Nevada, IA) so the workers could mimic the picking

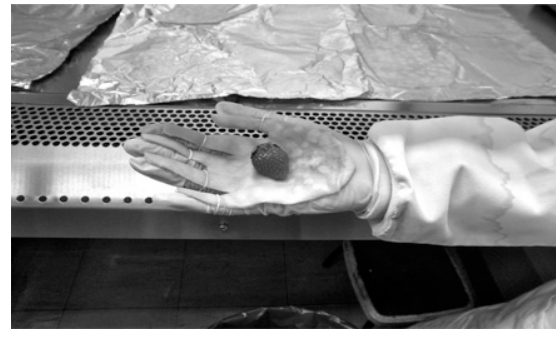

Fig. 1. Example of small pig skin "hand" $[16 \times 8.2 \mathrm{~cm}(6.3 \times 3.23$ inches)] used during the simulation of strawberry picking showing the size difference between the pig skin "hand" and strawberry.

process of the plant. Volunteers picked by snapping the pedicel stem with the finger tips for a treatment number of $1,10,20,30,40,50$, or 100 strawberries. The last strawberry picked of the treatments was used for microbial analysis and the previously picked strawberries were discarded (treatments $=7$ ). Each treatment was performed in duplicate and repeated on three separate times with different strawberry batches $(n=48)$. Within each treatment the last picked strawberry and the pig skin "hand" were placed within individual sterile stomacher bags and further analyzed. Each strawberry and "hand" were weighed and the appropriate amount of diluent, buffered peptone water (BPW), was added to the sample for obtaining a $1: 10$ dilution. Bacteria recovered from the diluent of the hands are recorded as cfu per hand, while bacteria recovered from the last strawberry is recorded as cfu per strawberry. The samples were stomached (Stomacher ${ }^{\circledR}$ 400C blender; Seward, Worthing, UK) at $230 \mathrm{rpm}$ for $90 \mathrm{~s}$ and serial dilutions were performed in BPW followed by plating onto MacConkey agar (MAC) with a thin tryptic soy agar overlay. This overlay technique was used in combination with the selective media (MAC) to capture any damaged E. coli $\mathrm{O} 17: \mathrm{H} 7$ during the process (Kang and Fung, 1999). The inoculated plates were incubated at $35 \pm 2{ }^{\circ} \mathrm{C}$ for $24 \mathrm{~h}$ and the emerged pink colonies were counted as E. coli O157:H7 colonies.

SCENARIO 2: TRANSFER OF “BACTERIA" FROM CONTAMINATED HANDS TO THE WORKER (SELFCONTAMINATION) AND TO THE FIELD. Visualization of the potential transfer of bacteria from contaminated hands 
to the worker and the field was performed in June 2012. The field plot consisted of 'Jewel' strawberry plants grown in a matted row production system. The row centers were spaced 42 inches apart (Iowa State University Horticulture Station). The study was designed to be a blind study. Therefore, the field workers were not told the nature and the purpose of the using of the GloGerm ${ }^{\text {TM }}$ powder (Glo Germ Co., Moab, UT) (referred to as glowing lotion) for avoiding any changes in the harvesting practices. On the morning of harvesting ( 5 June), five trained horticultural student workers (two males, three female) were asked to use a new "hand sanitizer." The "hand sanitizer" was a glowing lotion used to demonstrate the importance of hand washing. Before entering the fields to pick the strawberries, the glowing lotion was applied to the front and back of the workers' hands, and workers were asked to allow air drying the hands for $30 \mathrm{~s}$. The harvesters were supervised before entering the fields to ensure that the glowing lotion was not wiped off and workers did not touch other items before harvesting. The location of each individual worker and the number of rows picked were tracked as each harvester represented a separate replication. After the harvesting of the field was completed, the workers were taken into a dark room for assessing the glowing lotion transfer. A black light was used to determine the degree of self-contamination via visualization. The visualization of "bacteria" simulated by glowing lotion was completed in five replications or five workers over the 4-h harvesting period. Photographs were taken of each worker to highlight areas of cross contamination from their hands starting with the head and moving down over the body to their feet. The percent of observed cross contamination was based on visual assessment in the dark with black light $(0 \%$ to $100 \%)$ by taking pictures of each worker and measuring the amount of surface glowing found on their body. When night fell, the research team returned to the field with black lights to measure the presence of glowing lotion in each row harvested (fruit and/or foliage). Photographs of glowing areas were taken to capture the crosscontamination patterns within the field at the furthest point in the field were "glow" was shown.

Data analysis. Within the Scenario 1, the total E. coli $\mathrm{Ol}$ 57:H7 counts recovered after handling the strawberries using the pig skin "hands" were calculated. Logarithmic transformation was used for all data and transfer rates were calculated. The transfer rates were calculated using the following formula: percent transfer rate $=\mathrm{cfu}$ on strawberry/cfu on control hands $\times 100$ with the mean and standard deviation reported. Within Scenario 2, the distance that the bacteria surrogate, the glowing lotion, traveled via workers picking and moving through the rows was measured with measuring tape and analyzed using a general linear model for mean separation. Statistical analysis was performed using SAS (version 9.2; SAS Institute, Cary, NC).

\section{Results and discussion}

GAP recommendations encourage workers to wash hands before harvesting and after using the restroom, eating, drinking, touching surfaces or objects that may contain chemical or microorganisms, or using chemicals. Numerous research studies showed that the humans' hands may contain naturally foodborne bacteria (e.g., S. aureus) or can be contaminated as a result for lack of hygiene (Adesiyun et al., 1997; Al Bustan, et al., 1996; Mills et al., 2000). Observational studies have shown that growers who do not have hand-washing stations within the fields do not wash hands regularly (Ellis et al., 2005). Within the first scenario of our experiment the potential for E. coli $\mathrm{O} 157: \mathrm{H} 7$ to be transferred from contaminated pig skin "hands" onto the strawberries was observed $(P<0.05$; Table 1$)$. As the number of picked strawberries increased, the amount of E. coli O157: $\mathrm{H} 7$ that was transferred onto the strawberries decreased. Specifically, the first to 10th handled strawberries had a higher E. coli Ol57:H7 counts than any other treatment whereas the 50th to 100th handled strawberries had a lower E. coli Ol57:H7 counts than any of the other treatments $(P<$ $0.05)$. Transfer rates of the E. coli from the worker's pig skin "hands" to the strawberries decreased from $38.14 \%$, after one strawberry handled, to $29.13 \%$ after handling 100 strawberries. These results indicate that even with proper picking technique, bacteria transfer can occur between contaminated hands and berries.

Cross contamination between hands to the clothing and vectors within the field is another concern. This transfer of microorganisms can be done by simply wiping contaminated hands onto shirts, pants, hats, and bare skin. This phenomenon was shown within Scenario 2 through the

Table 1. Escherichia coli O157:H7 transferred from contaminated pig skin "hands" to strawberries during simulated harvesting. ${ }^{\mathrm{z}}$

\begin{tabular}{|c|c|c|c|}
\hline $\begin{array}{l}\text { Strawberries } \\
\text { handled (no.) }\end{array}$ & $\begin{array}{l}\text { E. coli O157:H7 recovered } \\
\text { from hands }\left[\log _{10} \text { mean } \pm \text { SE }\right. \\
(\mathrm{cfu} / \mathrm{mL} \text { per hand })]^{\mathrm{y}}\end{array}$ & $\begin{array}{l}\text { E. coli } \mathrm{O} 157: \mathrm{H} 7 \text { recovered from } \\
\text { last handled strawberry }\left[\log _{10} \text { mean } \pm \mathrm{SE}\right. \\
(\mathrm{cfu} / \mathrm{g} \text { per strawberry })]^{\mathrm{x}}\end{array}$ & $\begin{array}{l}\text { E. coli } \mathrm{O} 157: \mathrm{H} 7 \text { transferred } \\
\text { from hands to strawberry }(\%)\end{array}$ \\
\hline Control & $5.72 \pm 4.14$ & - & - \\
\hline 10 & $4.73 \pm 3.21$ & $2.10 \pm 1.78$ & 36.65 \\
\hline 20 & $4.88 \pm 3.18$ & $2.01 \pm 1.80$ & 35.07 \\
\hline 50 & $4.81 \pm 2.94$ & $1.37 \pm 1.53$ & 24.03 \\
\hline 100 & $4.76 \pm 2.18$ & $1.67 \pm 1.04$ & 29.13 \\
\hline
\end{tabular}

${ }^{\mathrm{z}}$ Means of three different sized worker hands and two replications for each worker were used for statistical analysis, repeated three times $(n=18)$.

yAmount of bacteria recovered from one hand; $1 \mathrm{cfu} / \mathrm{mL}=29.5735 \mathrm{cfu} / \mathrm{fl} \mathrm{oz}$.

${ }^{x}$ Amount of bacteria recovered from one strawberry; $1 \mathrm{cfu} / \mathrm{g}=28.3495 \mathrm{cfu} / \mathrm{oz}$. 

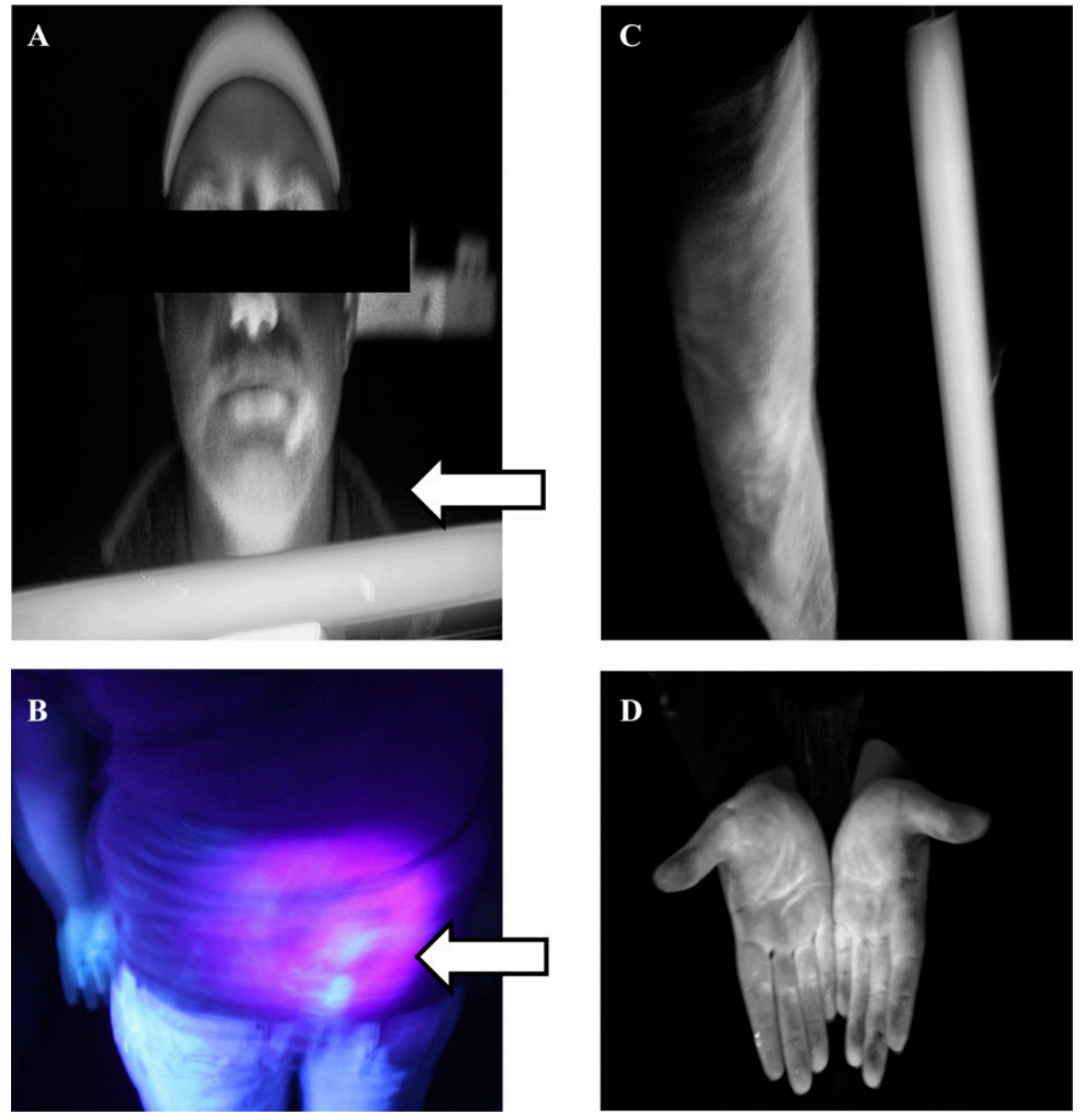

Fig. 2. Examples of worker self-contamination with glowing lotion ("bacteria") via contaminated hands during strawberry harvesting. The glow is from glowing lotion that was applied to workers' hands. (A) Image of a worker who may have touched mouth or eaten fruit within the fields during harvesting. (B) Image of shirt contamination from glowing lotion during harvesting. (C) Image of slacks contamination from glowing lotion during harvesting. (D) Worker hands after $4 \mathrm{~h}$ of harvesting in the field.

Table 2. Escherichia coli transferred from hands to body part as represented by percent of body part or clothing item touched by the worker self-contamination with glowing lotion ("bacteria") via contaminated hands during strawberry harvesting $(n=5)$.

\begin{tabular}{lcccccc}
\hline $\begin{array}{l}\text { Body part or } \\
\text { clothing item } \\
\text { observed }\end{array}$ & $\begin{array}{c}\text { Worker 1 } \\
\text { (female) }\end{array}$ & $\begin{array}{c}\text { Worker 2 } \\
\text { (female) }\end{array}$ & $\begin{array}{c}\text { Worker 3 } \\
\text { (male) }\end{array}$ & $\begin{array}{c}\text { Worker 4 } \\
\text { (male) }\end{array}$ & $\begin{array}{c}\text { Worker 5 } \\
\text { (male) }\end{array}$ & \begin{tabular}{c} 
Avg \\
\hline Face
\end{tabular} \\
\cline { 2 - 7 } & 1 & 1 & 1 & 1 & 1 & 1 \\
Hands (palm side) & 75 & 50 & 75 & 50 & 50 & 60 \\
Hat (entire) & 10 & $\mathrm{~N} / \mathrm{A}^{\mathrm{z}}$ & 10 & $\mathrm{~N} / \mathrm{A}$ & $\mathrm{N} / \mathrm{A}$ & - \\
Shirt (front) & 25 & 25 & 50 & 75 & 25 & 50 \\
Pants (front) & 50 & 1 & 10 & 25 & 25 & 25.2 \\
Shoes (top) & 10 & 10 & 10 & 10 & 10 & 10 \\
\hline
\end{tabular}

${ }^{z}$ Harvester was not wearing a hat during the experiment.

blind study with harvesters (Fig. 2). Extensive cross contamination was observed over the workers' outfit, but the degree of cross contamination varied on a portion of their face (i.e., ears, nose, mouth, or hair), their pants, shirt, and shoes (Table 2). Visual examples of this contamination are illustrated in Figure 2A where worker no. 1 may have eaten strawberries while harvesting. The hot summer day temperatures were also reflected in the presence of potential contamination from wiping sweat off of the exposed
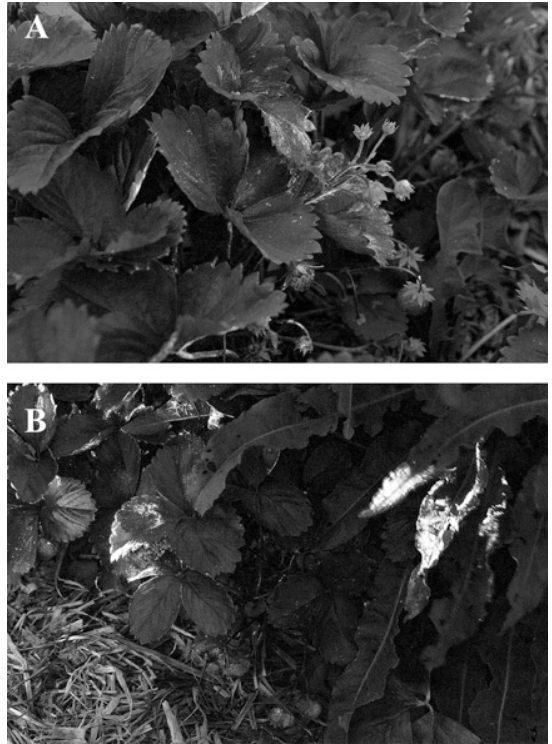

Fig. 3. Visualization of strawberry field after harvesting with glowing lotion contaminated hands. (A) Example of strawberry leaves and fruit contaminated by workers' hands during harvesting after $51 \mathrm{ft}(15.5 \mathrm{~m})$ out of harvesting. The glow is from glowing lotion that was applied to workers' hands. (B) Example of strawberry and weed leaves and straw mulch contaminated by workers hands during harvesting after $51 \mathrm{ft}$ of harvesting. The glow is from glowing lotion that was applied to workers' hands.

skin onto shirts and slacks (Fig. 2B and C). As the workers continued to pick, the presence of the bacteria-surrogate decreased and by the sixth, picked, 20lb flat box, the glow from the glowing lotion was hard to detect. Although not quantifiable, these results are the evidence that the contamination during normal picking scenario led to the transfer of the "bacteria" onto the strawberries. Additionally, Figure 3 provides evidence that after 4 -h of harvesting the risk for cross contamination still exists.

Within the fields, the contamination from the hands was observed up to $57 \mathrm{ft}$ measured from the end of the strawberry row on both the fruit and foliage. The distance range of matted row showing contamination via the five workers was $42-57 \mathrm{ft}$, with a mean of $50.25 \mathrm{ft}$. Figure $3 \mathrm{~A}$ and B illustrates the potential transfer from contaminated workers' hands to the entire field. The contamination was observed on the strawberry leaves and fruit, weeds, and mulch between strawberries rows. The glow due to the glowing lotion was detected at the highest contamination degree along 
edges of the fields where workers started the harvesting and faded as the workers moved into the field. This dilution effect over distance has been shown by other studies that evaluated the transfer rate of foodborne pathogens to objects (Buchholz et al., 2012; Patrick et al., 1997; Scott, 1990; Scott and Bloomfield, 1990), and could be contributed to the self-contamination observed by the workers and by the transfer to the strawberries.

It is common for berry growers to test their soil and water to ensure no pathogenic bacteria are present and to implement other GAP recommendations, such as manure application and wild life management. Hand hygiene is critical to prevent foodborne outbreaks and workers' training for food-safe harvesting are essential to ensure that the cross contamination does not occur. If the workers within the field scenario would have washed their hands before harvesting, as they were trained to do, then the presence of the glowing lotion would have been washed off and no contamination would have been seen. Our Scenario 2 experiment showed that as many as 100 strawberries can be cross contaminated with E. coli $\mathrm{O} 157: \mathrm{H} 7$ if handled with contaminated hands. The visualization of glowing lotion showed cross contamination from head to shoe, onto the strawberries, and in the field up to $57 \mathrm{ft}$ from the edge of the field. Employers and employees must be trained about the importance of hand hygiene before entering the fields, changing of tasks, or after any breaks. The implementation of these GAPs will help to ensure that contamination of strawberries or other field fruit does not occur. These two scenarios provide a useful tool for food safety educators and strawberry growers to demonstrate best practices during hand harvesting and can be used within their training program.

\section{Literature cited}

Adesiyun, A.A., L. Webb, and H.T. Romain. 1997. Relatedness of Staphylococcus aureus strains isolated from milk and human handlers in dairy farmer in Trinidad. J. Vet. Med. B 44:551-560.

Al Bustan, M.A., E.E. Udo, and T.D. Chugh. 1996. Nasal carriage of enterotoxinproducing Staphylococus aureus among restaurant workers in Kuwait city. Epidemiol. Infect. 116:319-322.

Alzamora, S., M. Tapia, and A. LopezMalo. 2000. Minimally processed fruits and vegetables. Aspen Publ., Gaithersburg, MD.

Barbero, A. and H. Frasch. 2008. Pig and guinea pig skin as surrogates for human in vitro penetration studies: A quantitative review. Toxicol. In Vitro 23:1-13.

Bihn, E. and R. Gravani. 2006. Role of good agricultural practices in fruit and vegetable safety, p. 116. In: M.P. Doyle (ed.). Microbiology of fresh produce. ASM Press, Washington, DC.

Buchholz, A.L., G.R. Marks, E.C.D. Todd, and E.T. Ryser. 2012. Quantitative transfer of Escherichia coli O157:H7 to equipment during small-scale production of fresh-cut leafy greens. J. Food Protection 75:1184-1197.

European Commission European Food Safety Authority. 2014. Scientific opinion on the risk posed by pathogens in food of non-animal origin. Part 2 (Salmonella and Norovirus in berry). EFSA J. 12:3706.

Ellis, J.D., C.H. Strohbehn, and D.H Henroid. 2005. Assessing on-farm food handling practices of Iowa-grown produce and eggs in regard to food safety. Food Protection Trends 25:758-761.

Kang, D. and D. Fung. 1999. Thin agar layer method for recovery of heat-injured Listeria monocytogenes. J. Food Protection 62:1346-1349.

Laury-Shaw, A., A. Svoboda, B. Jie, G. Nonnecke, and A. Mendonca. 2015. Survival of Eschericia coli on strawberries grown under greenhouse conditions. Food Microbiol. 46:200-203.

Mills, S., D. Holland, and A. Hard. 2000. Operative field contamination by the sweating surgeon. Austral. N. Z. J. Surg. 70:837-839.

Pate, M.L. and B. Nummer. 2013. Hand safety for specialty crop production workers: pilot study investigating frequencies of minor open-wound hand injuries and presence of pathogenic bacteria. J. Agr. Saf. Health 19(4):227-236.

Patrick, D., G. Findon, and T. Miller. 1997. Residual moisture determines the level of touch-contact-associated bacterial transfer following hand washing. Epidemiol. Infect. 119:319-325.

Rodriguez, M., A. Valero, G.D. PosadaIzquierdo, E. Carrasco, and G. Zurera. 2011. Evaluation of food handler practices and microbiological status of readyto-eat foods in long-term care facilities in the Andalusia region of Spain. J. Food Protection 74:1504-1512.

Scott, E. 1990. The survival of microbial contamination on work surfaces and cloths and its transfer via cloths hands and utensils. Environ. Health 98:34-37.

Scott, E. and S. Bloomfield. 1990. The survival and transfer of microbial contamination via cloths, hand and utensils. J. Appl. Bacteriol. 68:271-278.

Todd, E., J. Greig, C. Bartleson, and B. Michaels. 2008. Outbreaks where food workers have been implicated in spread of foodborne disease. Part 5. Sources of contamination and pathogen excretion from infected person. J. Food Protection 71:2582-2595.

Todd, E.C.D., B.S. Michaels, J. Holah, D. Smith, J.D. Greig, and C.A. Bartleson. 2010. Outbreaks where food workers have been implicated in the spread of foodborne disease. Part 10. Alcoholbased antiseptics for hand disinfection and a comparison of their effectiveness with soaps. J. Food Protection 73:2128-2140.

U.S. Food and Drug Administration. 1998. Guide to minimize microbial food safety hazards for fresh fruit and vegetables. Ctr. Food Safety Appl. Nutr., Washington, DC.

U.S. Food and Drug Administration. 2009. Guidance for industry: Guide to minimize microbial food safety hazards of leafy greens; Draft guidance. Ctr. Food Safety Appl. Nutr., Washington, DC. 